\title{
Recursos Familiares e o Desempenho Cognitivo dos Alunos do Ensino Básico Brasileiro*
}

\author{
José Francisco Soares \\ Ana Cristina Murta Collares
}

\section{INTRODUÇÃO}

\begin{abstract}
A participação ativa e crítica dos indivíduos na sociedade moderna A exige conhecimentos e competências que até há pouco tempo eram considerados necessários apenas para as elites intelectuais, em especial em países em desenvolvimento como o Brasil. Recentes avanços sociopolíticos nesses países conduziram a um novo consenso a respeito do papel preponderante dessas nações na promoção de oportunidades de aprendizado a todos os seus jovens e crianças. Educadores enfatizarão que a educação deve propiciar a aquisição das competências necessárias para a participação política esclarecida, a apreciação cultural, a manutenção das culturas locais, a difusão de atitudes de preservação ambiental e o respeito a diferenças, com a conseqüente busca de solução de conflitos pela via pacífica, além de impactar a saúde de todos. Os economistas, por outro lado, justificarão a universalização da educação escolar argumentando que a economia exige hoje uma força de trabalho mais educada e qualificada. Em qualquer destas
\end{abstract}

\footnotetext{
*José Francisco Soares registra e agradece à Fundação Ford pelo apoio institucional dado ao Grupo de Avaliação e Medidas Educacionais - GAME, da Universidade Federal de Minas Gerais - UFMG, e à Fundação Fullbright, que viabilizou seu estágio de pesquisa na University of Michigan-Ann-Arbor, onde a primeira versão deste texto foi redigida. Ana Cristina Murta Collares recebeu apoio da Coordenação de Aperfeiçoamento de Pessoal de Nível Superior - Capes para a realização deste estudo.
}

DADOS - Revista de Ciências Sociais, Rio de Janeiro, Vol. 49, nº3, 2006, pp. 615 a 481. 
visões, a escola é vista como a estrutura privilegiada para a aquisição dos conhecimentos e competências necessárias para a concretização das diferentes finalidades da educação.

No entanto, está muito bem estabelecido que o sucesso da escola como instituição é fortemente influenciado por fatores que lhe são externos. Isto porque o sucesso escolar dos estudantes está associado a características inatas a estes e, principalmente, às oportunidades que lhes são oferecidas pela família e pela sociedade em geral, antes e durante o seu período de escolarização. Estes fatos foram primeiramente observados em pesquisas empíricas conduzidas nos anos de 1950 e 1960. Nos Estados Unidos, destaca-se o trabalho que veio a ser conhecido como o "Relatório Coleman", pesquisa realizada com milhares de alunos norte-americanos (Coleman et alii, 1966; Mosteller e Moynihan, 1972); na Inglaterra, o "Relatório Plowden"; na França, o Instituto Nacional de Estudos Demográficos - INED, órgão governamental, conduziu um longo estudo longitudinal (1962-72) para avaliar as desigualdades de acesso aos estudos (Bressoux, 1994). Posteriormente, muitos estudos similares foram desenvolvidos em outros países com resultados semelhantes (Nogueira, 1990; Forquin, 1995), ou seja, reforçando a idéia de que os efeitos da família e das habilidades individuais dos alunos são superiores aos efeitos das escolas para explicar as diferenças de aprendizagem. Tais resultados sugerem que as análises de dados feitas com o objetivo de determinar o impacto dos fatores escolares no desempenho cognitivo dos alunos devem incluir nos seus modelos variáveis de controle, entre as quais se destaca a medida da posição social dos estudantes.

Se os fatores familiares entram nos modelos apenas com a função de controle estatístico, é razoável que apenas um indicador seja utilizado para descrever a influência da família no desempenho cognitivo dos estudantes. $\mathrm{O}$ indicador usualmente utilizado para sintetizar a influência da família é dominado pela condição econômica da mesma, e essa redução acaba prejudicando o estudo das políticas escolares e sociais que podem ser desenvolvidas através da parceria escola-família. Além disso, a ênfase no fator econômico traz uma mensagem subjacente e desnecessariamente pessimista de que não há nada a fazer em relação ao aprendizado dos alunos, sem a solução prévia da questão econômica de suas famílias.

Este artigo, utilizando-se de dados coletados em amostra representativa de alunos brasileiros do ensino básico, analisa e mede o impacto de 
diferentes fatores familiares associados ao melhor desempenho dos alunos. Reconhecendo explicitamente que a condição familiar é um conceito multidimensional, quatro categorias são propostas para descrevê-la: recursos econômicos da família; recursos culturais da família; o envolvimento dos pais com a educação dos filhos; e a composição da família, captada pela presença ou ausência de um ou ambos os pais.

Mais especificamente, nosso objetivo é identificar, com dados provenientes de estudantes e escolas brasileiros, evidências da existência de efeitos diretos e indiretos de cada um dos tipos de recursos familiares referidos anteriormente no desempenho dos alunos. De importância particular é a constatação de que a influência do fator econômico sobre o desempenho de estudantes se dá sobretudo de forma indireta. $\mathrm{Ou}$ seja, os recursos econômicos viabilizam a aquisição de recursos culturais e a participação dos pais na vida escolar dos filhos. Além disso, os dados são compatíveis com a hipótese de que o envolvimento dos pais desempenha o crucial papel de ativador dos recursos culturais familiares, tornando-os úteis para o desempenho cognitivo dos filhos. Estas constatações mostram que o impacto da ação dos pais na vida escolar dos filhos pode ser potencializado pela ação da escola através de programas especificamente voltados para a criação de atitudes educógenas nas famílias e também por políticas públicas na mesma direção.

\section{DADOS E MEDIDAS}

Os dados utilizados para a construção do modelo explicativo proposto provém do Sistema Nacional de Avaliação do Ensino Básico - Saeb. Este sistema foi planejado pelo governo federal para o monitoramento do ensino e, assim sendo, não coleta todas as informações que permitiriam medir de forma adequada os construtos explicativos do desempenho cognitivo dos estudantes, isto é, capital econômico, capital cultural e capital social das famílias dos alunos. Optamos, então, por usar categorias explicativas que denominamos de recursos econômicos, recursos culturais e envolvimento dos pais, formas restritas dos construtos explicativos mencionados.

\section{O SAEB}

O Saeb foi criado com o objetivo de subsidiar a elaboração de políticas educacionais nos níveis federal, estadual e municipal, ajudando a identificar variáveis associadas ao aprendizado e aos processos de en- 
sino. Iniciou-se em 1990 e desde 1993 tem sido realizado a cada dois anos. A partir de 1995, o Saeb utiliza uma amostra representativa dos alunos da quarta e oitava séries do ensino fundamental e do terceiro ano do ensino médio e a mesma escala para medir as proficiências em matemática e língua portuguesa, opção que permite a comparação de resultados de anos diferentes.

Os alunos das turmas das escolas incluídas na amostra respondem a um teste de língua portuguesa ou de matemática. Antes e depois do teste cognitivo, os alunos respondem a dois pequenos questionários contextuais, nos quais se coletam dados que permitem caracterizar os recursos econômicos e culturais presentes na família e o envolvimento dos pais com a educação de seus filhos. Além dos alunos, também os professores, o diretor e o responsável pela aplicação dos testes na escola preenchem questionários com informações variadas sobre a escola e sobre os que nela trabalham. Toda a informação coletada é confidencial, e os resultados são publicados apenas de forma agregada ou por estado da federação ou por todo o país. Em nenhuma hipótese, escolas específicas são identificadas.

A matriz de especificação dos itens incluídos nos testes do Saeb descreve a associação entre os conteúdos ensinados nas escolas brasileiras de ensino básico e as competências matemática e leitora que o teste procura medir. Para garantir a inclusão de itens referentes a todos os descritores, os testes do Saeb são organizados de modo que alunos diferentes façam testes diferentes, mas com itens comuns. A proficiência dos alunos é obtida pela estimativa de um parâmetro do modelo de três parâmetros da Teoria de Resposta ao Item para itens dicotômicos. Como o planejamento do teste inclui itens comuns entre as diferentes séries testadas e entre os diferentes anos, as proficiências dos alunos dos diferentes ciclos do Saeb, e das diferentes séries, podem ser expressas na mesma escala. Naturalmente, esperam-se valores menores nesta escala para alunos de quarta série e maiores para alunos de terceira série do ensino médio. As diferenças observadas ano a ano são resultado das intervenções feitas no sistema entre os intervalos de aplicação do teste, ou são fruto de variação amostral. A metodologia de construção da proficiência está descrita em Klein e Fontanive (1995). Em termos da medida da proficiência, o Saeb é particularmente competente.

Há uma literatura crescente sobre o Saeb. Para entender os aspectos da amostra utilizada, pode-se consultar o plano amostral do levantamen- 
to em Andrade, Silva e Bussab (2001). Franco (2001a) reúne um conjunto de artigos de reflexão crítica sobre o Saeb 1999. O planejamento do Saeb 2001 está descrito em Locatelli (2002), e os principais resultados, no relatório final divulgado pelo Instituto Nacional de Estudos e Pesquisas Educacionais - Inep (2001). O primeiro ciclo do Saeb foi avaliado por Maluf (1996) e os dois seguintes por Crespo, Soares e Souza (2000). Franco (2001b) apresenta propostas para a superação de algumas dificuldades presentes no Saeb na sua organização atual.

Os dados do Saeb são ainda os melhores existentes no Brasil para estudar as questões colocadas na introdução deste artigo. No entanto, têm limitações que precisam ser explicitadas. Primeiramente, deve-se observar que, dada a natureza do levantamento, há muitos dados ausentes. Por exemplo, na quarta série do ensino fundamental, aproximadamente 35\% dos alunos desconhecem o grau de escolaridade de seus pais. Tal limitação, aliada à necessidade de manter o maior número possível de alunos para a análise da associação entre as diferentes variáveis, foi um fator determinante na escolha dos modelos da Teoria de Resposta ao Item como técnica de medida dos construtos explicativos. Estes modelos, ao permitirem a medida do construto, mesmo para os alunos que responderam apenas alguns dos itens associados, produzem uma forma elegante e eficiente de tratamento de dados ausentes. Outra limitação estrutural dos dados é o fato de que estes provêm de respostas dos alunos a questões sobre suas respectivas famílias. Tecnicamente, temos apenas a visão do aluno sobre o valor da característica familiar, e não sua medida exata. Assim, ao fazer uso desses dados, assumimos que, embora a visão dos alunos não seja completamente precisa, não é viciada.

Neste artigo, usamos apenas os dados dos alunos de oitava série das escolas públicas, submetidos ao teste de matemática, que perfazem um total de 30.354 alunos divididos em 1.692 escolas de todas as regiões brasileiras. Diversas medidas foram construídas para viabilizar a análise das questões levantadas neste artigo, procurando captar características da família de cada aluno em suas diferentes dimensões, características individuais dos alunos e aspectos específicos de suas escolas. A construção das medidas utilizadas é explicitada nas próximas subseções, juntamente com as considerações teóricas que justificam a escolha das variáveis que fazem parte de cada construto. 


\section{RECURSOS ECONÔMICOS}

A renda familiar, muito freqüentemente chamada de capital econômico, é a primeira característica que deve ser considerada em estudos da influência da família no desempenho do aluno, principalmente em países como o Brasil, onde prevalecem altos graus de desigualdade de renda. No entanto, quando os dados disponíveis são obtidos através de questionários respondidos pelos alunos, não é possível conseguir esta informação. Os alunos simplesmente não conhecem a renda de sua família em nenhuma de suas definições usuais. Medidas indiretas devem, portanto, ser empregadas. Felizmente, a experiência internacional, sintetizada por Buchmann e Dalton (2002) e Willms (1992), mostra que escalas baseadas na existência de bens de conforto na casa do aluno fornecem medidas indiretas da renda familiar e completamente adequadas para o uso em pesquisas educacionais, ainda que estas não tenham uma interpretação monetária clara.

Uma abordagem alternativa à enumeração dos bens de conforto doméstico possuídos por uma família como forma de obter uma estimativa aproximada de seu capital econômico é usar a ocupação dos pais como indicador indireto de renda. Este dado tem a grande vantagem de ser de coleta mais neutra, menos invasiva do que a coleta de dados sobre a existência de bens na casa do aluno. A ocupação, depois de coletada e codificada, deve ser transformada, por exemplo, no International Socioeconomic Status Index - ISEI, um índice internacional que atribui a cada ocupação uma posição em uma escala que pode ser usada como proxy para a renda da família. Para detalhes sobre este índice, consultar Ganzeboom e Treiman (1996). No entanto, essa opção tem sido pouco usada, pois a coleta e codificação da informação sobre ocupações profissionais são tarefas complexas que requerem o uso de questões abertas no questionário contextual. Além disso, a experiência recente de uso deste indicador pelo Programme for International Student Assessment - PISA ${ }^{1}$ não é convincente, pois, nesse caso, para a análise final dos dados, se fez necessária a criação de um outro índice baseado no ISEI, no qual a informação de posse de bens de conforto doméstico foi também incluída.

Neste trabalho, considerando os itens disponíveis no questionário contextual do Saeb, compusemos um índice, representado pelo rótulo ou etiqueta "ECONO", com itens que captam se o aluno trabalha, se há empregadas domésticas na casa, a quantidade de banheiros, rádios, te- 
levisões em cores, videocassetes, geladeiras, freezers, aspiradores de pó, computadores, automóveis e o número médio de pessoas por quarto na residência do aluno. É razoável admitir que a presença destes itens na residência seja de conhecimento do aluno e que, portanto, suas respostas não sejam viciadas. A presença destes itens no questionário do Saeb justifica-se por serem todos já comumente utilizados em pesquisas sociais no Brasil. Eles fazem parte, por exemplo, da composição do índice de posição social, denominado Critério Brasil de Posição Social, introduzido pela Associação Nacional de Empresas de Pesquisa de Mercado. Neste estudo, entretanto, não utilizamos este índice, pois estamos interessados em analisar separadamente os componentes econômico e cultural da posição social.

No Apêndice deste artigo, mostramos o modelo da Teoria de Resposta ao Item e outros detalhes técnicos da construção da medida de recursos econômicos, bem como suas qualidades intrínsecas. Deve-se destacar, entretanto, que os itens utilizados fornecem forte evidência de que são determinados por apenas um único traço latente, o qual deve ser o capital econômico, já que todos os bens considerados exigem recursos financeiros para a sua aquisição.

\section{RECURSOS CULTURAIS}

As famílias que dispõem de recursos econômicos para adquirir outros bens, além daqueles estritamente necessários à sua subsistência, refletem nas suas opções de consumo seus valores intrínsecos. As famílias que valorizam a experiência escolar dos filhos aplicam proporcionalmente mais recursos financeiros na aquisição dos bens necessários para tornar o ambiente da casa mais adequado para o aprendizado dos filhos e procuram oferecer a estes experiências culturais e educacionais. Estas opções diferenciadas são atribuídas à quantidade de capital cultural possuída pelos pais.

O conceito de capital cultural, introduzido pelo sociólogo francês Pierre Bourdieu no famoso livro Les Héritiers (Bourdieu e Passeron, 1964), foi posteriormente tratado por ele em vários outros textos, sempre com adições de nuances e explicitações no seu significado. Entretanto, no seu conjunto, a obra de Bourdieu apresenta um conceito de capital cultural polissêmico, abstrato e de difícil uso em surveys educacionais realizados com vistas ao entendimento da proficiência de alunos. O uso do conceito de capital cultural da família com esta finalidade é consi- 
derado inadequado devido ao fato de que este já incorpora como uma de suas expressões a proficiência cognitiva dos filhos (Lareau e Weininger, 2003). Dentre as tentativas de operacionalizar quantitativamente o conceito de capital cultural, destaca-se a de Paul DiMaggio (1982), o qual operacionalizou o conceito de capital cultural como um traço latente medido através de itens que captam a participação dos estudantes em atividades de "alta cultura", tais como concertos, peças teatrais, visitas a museus e exposições culturais. Vários outros pesquisadores (e.g. De Graaf e De Graaf, 2000) passaram a usar essa operacionalização do conceito de capital cultural como uma categoria explicativa para o desempenho escolar. Embora seja intuitivamente aceitável, os resultados da utilização desta visão mais operacional de capital cultural nem sempre têm sido positivos. Por exemplo, nos questionários contextuais do PISA foram introduzidos itens similares aos usados por DiMaggio, mas estes não foram capazes de capturar o capital cultural familiar em países nos quais a participação dos jovens nos eventos de alta cultura não é tão freqüente. No Brasil especificamente, refletindo a pequena freqüência desse tipo de evento entre os estudantes, mesmo aqueles que freqüentam as escolas particulares, estes itens não se mostraram adequados para medir a existência de "recursos culturais na residência" das famílias brasileiras, mostrando que as noções de "alta" e "baixa" cultura podem variar significativamente de uma sociedade para outra.

Mediante a experiência negativa do PISA, o questionário contextual do aluno no Saeb 2001 incluiu perguntas que verificaram a disponibilidade em casa de itens que refletem preocupações intelectuais das famílias brasileiras, tais como: livros (além dos exigidos pela escola), um lugar calmo para estudar, revistas de informação geral, jornal diário, enciclopédia, atlas, dicionário e calculadora. Assim, o construto utilizado no presente estudo não enfatiza a participação na "alta cultura", mas sim o consumo de itens que favorecem a aquisição de conhecimento acadêmico na residência, tais como livros e computadores. Para evitar confusões teóricas com outras concepções de capital cultural, vamos chamar a este construto de "recursos culturais na residência" e representá-lo pela etiqueta "CULTURAL".

Nesse estudo, além desses itens de consumo cultural tomaram-se também as escolaridades do pai e da mãe do aluno como indicadores de recursos culturais na residência. Os detalhes da construção da medida estão registrados no Apêndice. 


\section{ENVOLVIMENTO DOS PAIS}

Coleman (1988) sugere que a transmissão de capital cultural exige constantes interações entre pais e filhos, principalmente em situações nas quais o objetivo é o consumo de bens culturais. Naturalmente, interações similares com outros adultos também ajudam. Por isso, Coleman denominou "capital social" aos recursos gerados pela oportunidade de conviver com adultos detentores de capital cultural. O conceito de capital social, embora originário da sociologia da educação, foi adaptado a muitas outras áreas da sociologia e é hoje amplamente utilizado com significados bastante variados (e.g. Putnam, 1993). Assim sendo, a fim de evitar confundir o construto utilizado neste artigo com uma das diversas interpretações do conceito de capital social, vamos denominá-lo de "envolvimento dos pais" e representá-lo pela etiqueta "PAIS".

O envolvimento dos pais na vida escolar de seus filhos é medido aqui através de itens que registram o tempo gasto pelos pais conversando com os filhos sobre livros, filmes, programas de TV, assuntos gerais, ouvindo música, almoçando ou jantando, conversando sobre o que acontece na escola, ajudando na lição de casa, cobrando se o filho fez a lição de casa, cuidando para que o filho não chegue atrasado na aula e incentivando-o a tirar boas notas. Embora todos os itens possam ser descritos basicamente por um único fator, vale observar que um segundo fator que enfatizaria a diferença entre o envolvimento dos pais com a vida escolar e com as atividades mais rotineiras dos filhos também aparece na análise da matriz de correlação entre os itens, ainda que de maneira mais fraca. Os detalhes da construção deste fator estão no Apêndice.

\section{OUTRAS CARACTERÍSTICAS DA FAMÍLIA}

Além dos construtos apresentados nas seções anteriores, outras características familiares também estão associadas ao desempenho escolar dos alunos, embora muitas delas não sejam incluídas neste artigo devido a limitações dos dados. Muitos trabalhos mostram, por exemplo, que o tamanho da família está negativamente associado ao desempenho do aluno, já que uma família grande não pode prover os mesmos recursos financeiros, culturais e sociais para todos os seus filhos. A consideração deste fator, entretanto, exige uma medida do tamanho da família, não disponível no Saeb. 
Pesquisas empíricas como a descrita por Lareau (1989) têm mostrado que outras facetas da organização familiar concorrem para um melhor ou pior desempenho escolar. A influência das estruturas da rotina diária, do clima emocional prevalente no lar e da presença de estresse na família não deve, portanto, ser minimizada. Tradicionalmente, essas influências são capturadas por diversos indicadores. Indicadores da organização da família, que incluem a presença de regras para o comportamento, a existência de alguma previsibilidade nos horários dos eventos diários, a certeza de que os membros da família cumprirão suas obrigações, a pontualidade e a aparência física e limpeza das pessoas e da casa. Indicadores do clima emocional da família incluem informações a respeito da visão da criança sobre as relações entre os pais, a abordagem educacional dos pais (mais punitiva ou mais educativa) e a freqüência com que as crianças têm oportunidades para se divertir sozinhas ou acompanhadas dos pais. Indicadores de estresse familiar incluem presença de dificuldades financeiras, perdas recentes de membros familiares queridos, doenças e presença de dependência química entre membros da família. No entanto, estes indicadores só podem ser adequadamente coletados através de entrevistas com os pais ou diários dos alunos. Como estas formas de coletas são caras, poucas vezes é possível examinar o impacto real destas variáveis no desempenho cognitivo de alunos em grandes amostras, tais como a do Saeb.

Uma característica freqüentemente estudada, e que pôde ser captada através de uma variável coletada pelo Saeb, é a presença na vida diária do aluno de ambos os pais. A ausência de um dos pais, seja pela ocorrência de divórcio, por opção da mãe, ou por abandono do pai, impacta negativamente o desempenho do aluno, como discutido por Garib, Garcia e Dronkers (2003). O efeito deletério da ausência de um dos pais é, entretanto, diminuído nas sociedades que têm uma rede de proteção social eficiente. O questionário do Saeb permite a construção de apenas uma variável que capta a qualidade do contato do aluno com um ou ambos os pais. Assim, neste estudo, a variável que indica a presença ou ausência de ambos os pais na residência do aluno foi utilizada como um indicador da composição familiar denominada "FAMÍLIA".

\section{CARACTERÍSTICAS DO ALUNO}

O objetivo principal deste artigo é estudar não apenas a interação das diferentes dimensões da estrutura familiar com o desempenho escolar dos alunos do ensino básico brasileiro mas, principalmente, a intera- 
ção destas dimensões. No entanto, o aprendizado é característica do aluno, não da sua família. A família pode criar as condições adequadas e ser bem-sucedida na correta motivação do aluno, mas é ele quem adquire ou não o conhecimento, medido na escala de proficiência. Diante disto, o estudo dos fatores familiares associados ao desempenho cognitivo exige a consideração concomitante de algumas características do aluno. Usando as experiências anteriores com a análise de dados do Saeb (Soares et alii, 2001) e considerando a literatura pertinente e os itens disponíveis no questionário contextual do Saeb, incluímos na análise as seguintes variáveis medidas para cada aluno constante da amostra: sexo, um indicador de cor/raça, uma medida da atitude do aluno em relação à escola e uma medida do atraso escolar.

Ainda observa-se no Brasil uma diferença marcante entre os sexos em termos de desempenho cognitivo: os alunos do sexo masculino têm melhor desempenho em matemática, e os do sexo feminino, em língua portuguesa. Quanto à cor/raça, o questionário do Saeb pede ao aluno que indique, dentre as opções: branco, pardo, preto, amarelo e indígena, aquela que melhor o descreve. Neste artigo sintetizamos esta informação em uma variável indicadora que registra se o aluno se declara branco ou amarelo em oposição às outras opções. Como mostram Soares e Alves (2003), esta agregação não é adequada se o foco da análise é o estudo do impacto da cor/raça do aluno no seu desempenho acadêmico. Sabe-se que a atitude do aluno em relação à escola é crucial para o aprendizado. Esta atitude é, neste estudo, captada pela sua resposta a dois itens presentes no questionário: se ele gosta da disciplina na qual foi avaliado, aqui matemática, e se faz os deveres de casa. Finalmente, incluímos no modelo uma medida de anos de atraso escolar, ou seja, a diferença entre a idade do aluno e a idade esperada para a oitava série. A presença de atraso escolar é uma indicação, ainda que primária, do fraco desempenho do aluno em anos anteriores.

\section{CARACTERÍSTICAS DA ESCOLA}

A aprendizagem de conteúdos cognitivos ocorre principalmente na escola. Por isso, os modelos explicativos do desempenho escolar de estudantes devem incluir, como variáveis explicativas, algumas características das escolas. Além das diferenças no projeto pedagógico, existem diferenças marcantes entre as escolas em relação a indicadores construídos através da agregação de características dos alunos. Assim, podemos nos referir ao nível socioeconômico da escola, definindo-o 
como a média do nível socioeconômico de todos os seus alunos. Seguindo esse mesmo raciocínio, neste estudo construímos quatro indicadores socioculturais da escola, calculando o valor médio de cada uma (tomado a partir do conjunto de alunos da escola) em relação aos indicadores ECONO, CULTURAL, PAIS e ATRASO registrados para cada aluno.

Como nossa ênfase é colocada no estudo das inter-relações entre os fatores familiares, as variáveis escolares incluídas no modelo de análise têm função apenas de controle estatístico dos valores apresentados por cada escola em relação a essas variáveis, ou seja, a inclusão destas no modelo procura reduzir as diferenças entre as escolas que podem influenciar na análise. Diante disso, sem perder generalidade, mas tornando a análise mais simples, optamos por reduzir os quatro indicadores socioculturais da escola a um, denominando-o de "homogeneidade sociocultural da escola". Este fator foi construído através de uma análise fatorial clássica nas quatro variáveis: ECONO, CULTURAL, PAIS e ATRASO, agregadas ao nível da escola.

As escolas com valores mais altos neste fator têm alunos com perfil socioeconômico cultural mais favorável e, por isto, atraem melhores professores e conseguem mais recursos. Além disso, a convivência diária entre alunos com altos valores naqueles quatro indicadores acaba produzindo um efeito cognitivo positivo em todos os elementos do grupo. Este é o chamado efeito dos pares, cuja existência já foi amplamente corroborada na literatura internacional (Hanuschek et alii, 2003), bem como na literatura nacional (Soares, T.M., 2003).

A Tabela 1 apresenta a síntese das variáveis utilizadas, bem como a sua etiqueta, usada extensivamente nas próximas seções.

Para maior simplicidade na apresentação de alguns resultados, optamos por trabalhar com as variáveis padronizadas, ou seja, usar o escore padronizado de cada variável. Para tornar esta opção clara, usaremos, para nos referir às variáveis padronizadas, as etiquetas da Tabela 1 precedidas da letra Z. Por exemplo, usaremos ZECONO para nos referir ao escore padronizado do fator econômico.

\section{RESULTADOS E ANÁLISES}

\section{Associação entre os Fatores Considerados}

A Tabela 2 mostra o coeficiente de correlação de Pearson entre os construtos do estudante e de sua família. O maior coeficiente ocorre entre o 
Recursos Familiares e o Desempenho Cognitivo dos Alunos...

Tabela 1

Caracterização das Variáveis Usadas no Estudo*

\begin{tabular}{|c|c|c|}
\hline $\begin{array}{c}\text { Nível da } \\
\text { Característica }\end{array}$ & Descrição da Variável & Código da Variável \\
\hline \multirow{5}{*}{ Estudante } & Sexo: 0 - Homem 1 - Mulher & SEXO \\
\hline & Raça: 0 - Branco ou Amarelo 1 - Outras & RAÇA \\
\hline & Atitude em relação à escola: Escala TRI & ATITUDE \\
\hline & Atraso: defasagem escolar em anos & ATRASO \\
\hline & Proficiência: desempenho: Escala TRI & PROFICT \\
\hline \multirow{4}{*}{ Família } & \multirow{4}{*}{$\begin{array}{l}\text { Recursos culturais: Escala TRI } \\
\text { Recursos econômicos: Escala TRI } \\
\text { Participação dos pais: Escala TRI } \\
\text { Estrutura familiar: } 0 \text { - Ausência de um pai } \\
1 \text { - Presença de ambos }\end{array}$} & CULTURAL \\
\hline & & ECONO \\
\hline & & PAIS \\
\hline & & FAMÍLIA \\
\hline \multirow[t]{2}{*}{ Escola } & $\begin{array}{l}\text { Homogeneidade socioeconômica: análise } \\
\text { fatorial }\end{array}$ & ESCOLA \\
\hline & Localização: 0 - Interior 1 - Capital & LOCAL \\
\hline
\end{tabular}

Fonte: Síntese dos dados do Saeb, elaborada pelos autores.

* As variáveis construídas pela TRI ou análise fatorial assumem valores entre -3 e 3 .

índice de recursos econômicos e o de recursos culturais. Isto reflete o fato de ambos os construtos serem medidos pela posse de bens, no primeiro caso, bens de conforto doméstico e, no segundo, bens culturais. Apesar desta similaridade, quando se analisa a dimensionalidade da matriz de correlação entre todos os itens utilizados para medir ambos os construtos, constata-se a existência de dois fatores. Os itens apontados por esta análise conjunta para compor os dois indicadores são exatamente os escolhidos pela análise aqui relatada para representar o nível econômico e a existência de recursos culturais na residência do estudante. Há, portanto, claras evidências empíricas da existência de dois construtos latentes nas respostas dos alunos, apesar de serem associados.

O atraso escolar está negativamente associado com todos os outros construtos. Este resultado é esperado, já que esta variável pode ser considerada como uma proxy do desempenho do aluno em anos anteriores. O sinal negativo mostra que os alunos com atraso escolar são freqüentemente filhos de famílias de poucos recursos econômicos, culturais e sociais. 
Tabela 2

Coeficientes de Correlação de Pearson entre Construtos Considerados

\begin{tabular}{c|c|c|c|c|c|c}
\hline & ZECONO & ZCULTO & ZPAIS & ZATITUDE & ZATRASO & ZPROFICT \\
\hline ZECONO & 1,00 & 0,51 & 0,18 & 0,01 & $-0,31$ & 0,25 \\
ZCULTO & 0,51 & 1,00 & 0,32 & 0,07 & $-0,24$ & 0,23 \\
ZPAIS & 0,18 & 0,32 & 1,00 & 0,20 & $-0,19$ & 0,11 \\
ZATITUDE & 0,01 & 0,07 & 0,20 & 1,00 & $-0,10$ & 0,20 \\
ZATRASO & $-0,31$ & $-0,24$ & $-0,19$ & $-0,10$ & 1,00 & $-0,31$ \\
ZPROFICT & 0,25 & 0,23 & 0,11 & 0,20 & $-0,31$ & 1,00 \\
\hline
\end{tabular}

Fonte: Resultado de ajustes de modelos estatísticos realizados pelos autores.

Os coeficientes de correlação entre os construtos e a proficiência do aluno são pequenos, mas estão na ordem de grandeza usualmente observada na literatura. Isto informa apenas que cada uma destas variáveis, apesar de estar associada de forma significativa à proficiência, não é, sozinha, uma boa preditora da mesma. O desempenho cognitivo do aluno, embora associado a variáveis da família e da escola, depende de muitas outras variáveis associadas ao aluno, a maioria das quais impossível de ser medida através de questionários auto-aplicados. Diante disto, modelos que usam apenas variáveis obtidas em processos de monitoramento do sistema escolar não têm grande capacidade preditiva para um resultado tão complexo como a proficiência de estudantes.

Os coeficientes de correlação exibidos na Tabela 2 foram calculados utilizando todos os alunos das escolas públicas incluídos na amostra do Saeb-2001, com os pesos especificados no plano amostral. Dentre esses alunos existem aqueles que são muito pobres. Para estes, podemos suspeitar que as associações entre os construtos descritos não ocorrem da forma esperada. No entanto, ao calcularmos a matriz de correlação excluindo os alunos que possuem valor mais baixo no fator econômico, que correspondem a $10 \%$ do total, ela se mantém praticamente inalterada.

\section{ANÁLISE HIERÁRQUICA}

Visando captar a associação entre o desempenho cognitivo dos alunos e fatores familiares, o primeiro modelo de análise considerado é uma regressão da proficiência no teste de matemática com fatores explicativos familiares, ou seja, os indicadores de recursos econômicos, culturais e de envolvimento dos pais. Além desses, considerando os resulta- 
dos já constatados na literatura, incluímos também como variáveis explicativas o sexo, a cor / raça e atitude em relação à escola, bem como a variável construída para captar a heterogeneidade sociocultural dos alunos da escola.

Como os alunos estão agregados por escolas, o modelo adequado é o de regressão hierárquica, que considera, na estimação dos parâmetros, a dependência existente entre as respostas dos alunos pertencentes a uma mesma escola. Para a descrição desse modelo veja-se Lee (2000), Goldstein (2003) e Raudenbush e Bryk (2002). No processo de construção de modelos explicativos, considerando o elevado número de alunos da amostra, isto é, 30.354, utilizamos o nível de 0,001 como valor mínimo para atribuição de significância estatística ao coeficiente.

O modelo final utilizado é:

Modelo de nível 1: aluno

ZPROFICT $=\mathrm{B} 0+\mathrm{B} 1 *(\mathrm{ZSEXO})+\mathrm{B} 2 *(\mathrm{ZRAÇA})+\mathrm{B} 3 *(\mathrm{ZCULTO})+$ $\mathrm{B} 4 *($ ZATRASO $)+\mathrm{B}^{*}($ ZATITUDE $)+\mathrm{R}$

Modelo de nível 2: escola

$\mathrm{B} 0=\mathrm{G} 00+\mathrm{G} 01^{*}(\mathrm{ZESCOLA})+\mathrm{U} 0$

A Tabela 3 apresenta as estimativas dos parâmetros do modelo. Como todas as variáveis estão padronizadas, os valores das estimativas dos parâmetros podem ser comparados entre si. Estes são semelhantes ao coeficiente "beta" no modelo de regressão linear múltipla e indicam o tamanho da mudança, em termos de desvio padrão, na variável resposta por uma mudança de um desvio padrão em cada variável explicativa.

As estimativas apresentadas na Tabela 3 mostram que alunos do sexo masculino têm melhor desempenho em matemática que os do sexo feminino, alunos que se declaram brancos ou amarelos têm melhor desempenho do que os demais, os que estão atrasados em relação à série escolar têm pior desempenho. A presença de ambos os pais na casa está associada a um melhor desempenho, mesmo entre alunos com condição econômica semelhante. Alunos com melhor atitude em relação à escola também têm melhor desempenho. Deve-se observar ainda que, neste modelo, os recursos econômicos da família não impactam diretamente de forma significativa o desempenho dos alunos. $\mathrm{O}$ fator mais 
Tabela 3

Estimativas dos Parâmetros do Modelo e Respectivos Desvios-Padrão

\begin{tabular}{l|c|c|c|c|c|c}
\hline $\begin{array}{l}\text { Termos do } \\
\text { Modelo }\end{array}$ & Notação & Coeficiente & $\begin{array}{c}\text { Desvio } \\
\text { Padrão }\end{array}$ & Razão-T & $\begin{array}{c}\text { Graus de } \\
\text { Liberdade }\end{array}$ & Valor-P \\
\hline INTERCEPTO & G00 & $-0,075$ & 0,010 & $-7,44$ & 1.690 & 0,000 \\
\hline ZESCOLA & G01 & 0,302 & 0,011 & 26,56 & 1.690 & 0,000 \\
\hline ZSEXO & B1 & $-0,161$ & 0,015 & $-10,82$ & 30.346 & 0,000 \\
\hline ZRAÇA & B2 & 0,052 & 0,010 & 5,20 & 30.346 & 0,000 \\
\hline ZCULTO & B3 & 0,076 & 0,014 & 5,31 & 30.346 & 0,000 \\
\hline ZATRASO & B4 & $-0,184$ & 0,012 & $-14,57$ & 30.346 & 0,000 \\
\hline ZATITUDE & B5 & 0,147 & 0,013 & 11,33 & 30.346 & 0,000 \\
\hline ZFAMÍLIA & B6 & 0,075 & 0,010 & 7,01 & 30.346 & 0,000 \\
\hline
\end{tabular}

Fonte: Resultado de modelos estatísticos ajustados pelos autores.

associado com o desempenho é o indicador da homogeneidade sociocultural dos alunos da escola. Este é o chamado "efeito dos pares", isto é, alunos com melhor perfil acadêmico potencializam mutuamente seus conhecimentos em benefício de todos. Esse efeito também capta a maior capacidade de articulação política e social entre pais com melhor condição econômica, que se traduz em mais recursos na escola de seus filhos.

A análise destes dados via um modelo de regressão não permite a explicitação da associação existente entre os diferentes fatores familiares como parte substantiva do mecanismo explicativo da ação da família no desempenho dos estudantes. A ausência no modelo final de regressão tanto do fator econômico quanto do envolvimento dos pais indica que estes fatores devem afetar os resultados apenas de forma indireta. Para explicitar estas importantes relações entre os fatores, é preciso utilizar modelos de análise que permitam a consideração conjunta de várias respostas ou resultados intermediários, e não apenas da resposta final, que, nesse caso, é a proficiência do aluno. Um tipo de modelo estatístico adequado para esse objetivo é a chamada análise de trajetória, que combina diversas equações estruturais com diferentes variáveis resposta em um só modelo e torna possível o estabelecimento de uma trajetória causal entre os fatores. Os resultados do modelo baseado na análise de trajetória que utilizamos neste trabalho são apresentados na próxima seção. 


\section{MODELOS ESTRUTURAIS}

Para formular um modelo para as inter-relações dos fatores explicativos apresentados nas seções anteriores é necessário primeiro classificá-los em variáveis exógenas ou endógenas na notação usual da literatura de modelos estruturais (e.g. Hayduk, 1987). Os fatores endógenos são aqueles que desempenham o papel de variável resposta em alguma das associações a serem estudadas e os exógenos são os que funcionam apenas como variável explicativa em alguma destas mesmas associações. Consideramos endógenos os seguintes fatores: proficiência (y1: PROFICT); recursos culturais na residência do aluno (y2: CULTURAL); envolvimento dos pais (y3: PAIS); atitude em relação à escola (y4: ATITUDE); atraso escolar (y5: ATRASO); e o índice de homogeneidade sociocultural da escola (y6: ESCOLA). Consideramos como exógenos o fator de recursos econômicos da família (x1: ECONO) e as variáveis de caracterização do aluno, ou seja, a composição da família (x2: FAMÍLIA); o sexo (x3: SEXO); a cor da pele ( $x 4$ : RAÇA); e a localização da escola (x5: LOCAL).

O modelo proposto para a associação entre essas variáveis considerou as seguintes hipóteses, provenientes da literatura: a proficiência é uma medida da competência matemática do aluno adquirida principalmente na escola; a família do aluno influencia sua atitude em relação à escola e desempenha papel crucial na escolha da escola do filho. Atitudes positivas em relação à escola são mais presentes em famílias nas quais os pais estão realmente envolvidos com a educação de seus filhos, postura certamente influenciada pelo seu capital cultural. No entanto, para que esta cadeia de decisões familiares ocorra, é necessário que a família disponha de recursos econômicos, além daqueles necessários para a sua sobrevivência. O atraso escolar é tomado como uma medida ainda que precária do desempenho prévio do aluno e é naturalmente influenciado pela estrutura da família e pelos seus recursos econômicos.

Esses fatos substantivos iniciais, com o auxílio de diversos resultados empíricos obtidos pelo uso do software para ajuste de modelos de equações estruturais, conduziram ao modelo final, definido pelas seis equações de regressão apresentadas a seguir:

PROFICT $=\beta_{14}($ ATITUDE $)+\beta_{15}($ ATRASO $)+\beta_{16}($ ESCOLA $)+$ $\gamma_{12}($ FAMÍLIA $)+\gamma_{13}($ SEXO $)+\gamma_{14}($ RAÇA $)+\zeta_{1}$ 
CULTURAL $=\gamma_{21}($ ECONO $)+\gamma_{25}($ LOCAL $)+\zeta_{2}$

PAIS $=\beta_{32}($ CULTURAL $)+\beta_{35}($ ATRASO $)+\zeta_{3}$

ATITUDE $=\beta_{43}($ PAIS $)+\zeta_{4}$

ATRASO $=\beta_{56}($ ESCOLA $)+\gamma_{51}($ ECONO $)+\gamma_{52}($ FAMÍLIA $)+\gamma_{53}($ SEXO $)+$ $\zeta_{5}$

$\mathrm{ESCOLA}=\beta_{62}(\mathrm{CULTO})+\beta_{63}(\mathrm{PAIS})+\gamma_{61}(\mathrm{ECONO})+\zeta_{6}$

A estimação dos parâmetros deste modelo foi feita no software LISREL, e o Quadro 1 apresenta as estimativas dos coeficientes das equações do

Quadro 1

Estimativas dos Coeficientes das Equações do Modelo Estrutural

\begin{tabular}{|c|c|c|c|c|c|c|}
\hline \multicolumn{7}{|c|}{ Variáveis Endógenas } \\
\hline & PROFICT & CULTO & PAIS & ATITUDE & ATRASO & ESCOLA \\
\hline PROFICT & $--\quad-$ & -- & --- & 0,17 & $-0,18$ & 0,22 \\
\hline CULTO & --- & --- & --- & -- & -- & -- \\
\hline PAIS & -- & 0,30 & $--\quad-$ & -- & $-0,09$ & - - - - \\
\hline ATITUDE & --- & --- & 0,20 & --- & $--\quad-$ & $--\quad--$ \\
\hline ATRASO & -- & -- & -- & -- & -- & $-0,37$ \\
\hline ESCOLA & -- & 0,22 & 0,10 & -- & -- & $--\quad--$ \\
\hline \multicolumn{7}{|c|}{ Variáveis Exógenas } \\
\hline & ECONO & FAMÍLIA & SEXO & RAÇA & LOCAL & \\
\hline PROFICT & -- & 0,09 & $-0,16$ & 0,07 & -- & \\
\hline CULTO & 0,51 & $--\quad--$ & $--\quad--$ & $--\quad--$ & 0,11 & \\
\hline PAIS & -- & --- & --- & --- & --- & \\
\hline ATITUDE & -- & -- & -- & -- & -- & \\
\hline ATRASO & $-0,11$ & $-0,12$ & $-0,09$ & --- & $--\quad-$ & \\
\hline ESCOLA & 0,39 & -- & --- & -- & -- & \\
\hline
\end{tabular}


Figura 1

Modelo de Associação entre Fatores Familiares e Escolares e o Desempenho em Matemática

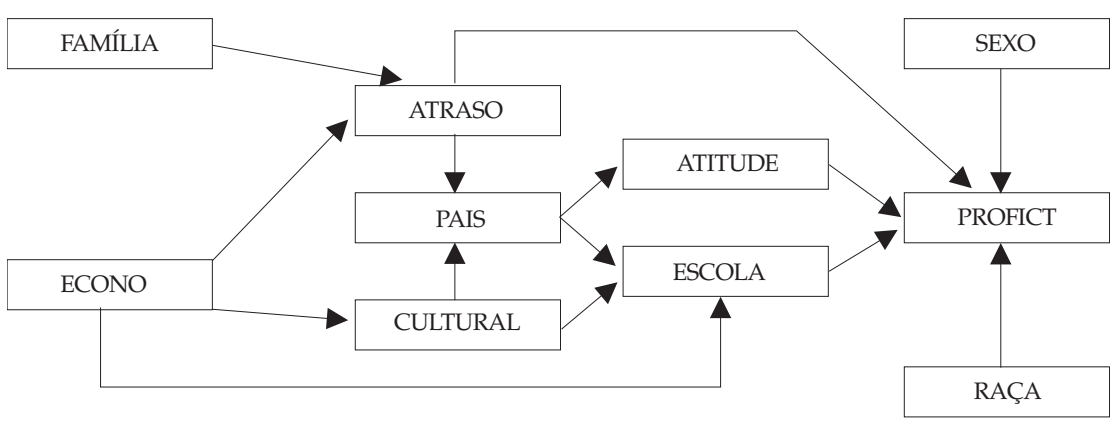

modelo estrutural. Todos os valores desse quadro são comparáveis e representam o efeito direto, em termos de desvio padrão, na variável resposta por uma mudança de um desvio em cada variável explicativa. Usualmente, valores menores que 0,10 são considerados pouco relevantes.

Este modelo é melhor compreendido na sua forma gráfica, apresentada na Figura 1, na qual as associações não relevantes estão omitidas.

As setas da figura indicam os efeitos diretos da variável de origem na variável de destino da seta. Por exemplo, o fator ECONO tem impacto direto apenas sobre os fatores ATRASO e CULTURAL. Além do efeito direto de um fator, podemos falar do efeito indireto. Por exemplo, embora o fator ECONO não tenha efeito direto na resposta PROFICT, tem efeito indireto através das variáveis ATRASO e CULTURAL que, por sua vez, está relacionada à variável ATITUDE e esta, finalmente, à proficiência. O entendimento dessa figura é crucial para apreciar as conclusões substantivas deste estudo.

O Quadro 2 apresenta o efeito total padronizado das variáveis endógenas e exógenas. Por exemplo, o efeito total do fator ECONO sobre a proficiência é de 0,18 . Isto indica que uma mudança de um desvio padrão no valor do fator ECONO induz uma mudança de 0,18 desvio padrão na proficiência (PROFICT). Os outros coeficientes têm interpreta- 
ção análoga. Os efeitos acima de 0,10 , um limite usual para classificar os efeitos como relevantes, foram destacados em negrito no Quadro 2.

Quadro 2

Efeito TOTAL Padronizado das Variáveis Endógenas e Exógenas

\begin{tabular}{|c|c|c|c|c|c|c|}
\hline \multicolumn{6}{|c|}{ Efeito Total de $X$ em Y } & \\
\hline & ECONO & FAMILIA & SEXO & RAÇA & LOCAL & \\
\hline PROFICT & 0,18 & 0,11 & $-0,14$ & 0,07 & 0,01 & \\
\hline CULTO & 0,51 & --- & $--\quad-$ & --- & 0,11 & \\
\hline PAIS & 0,18 & 0,01 & 0,01 & -- & 0,03 & \\
\hline ATITUDE & 0,04 & 0,00 & 0,00 & --- & 0,01 & \\
\hline ATRASO & $-0,30$ & $-0,12$ & $-0,09$ & --- & $-0,01$ & \\
\hline ESCOLA & 0,52 & 0,00 & 0,00 & -- & 0,03 & \\
\hline \multicolumn{7}{|c|}{ Efeito Total de $Y$ em $Y$} \\
\hline & PROFICT & CULTO & PAIS & ATITUDE & ATRASO & ESCOLA \\
\hline PROFICT & -- & 0,08 & 0,06 & 0,17 & $-0,18$ & 0,29 \\
\hline CULTO & --- & --- & $--\quad-$ & -- & --- & $--\quad--$ \\
\hline PAIS & --- & 0,31 & 0,00 & --- & $-0,09$ & 0,03 \\
\hline ATITUDE & -- & 0,06 & 0,20 & -- & $-0,02$ & 0,01 \\
\hline ATRASO & --- & $-0,09$ & $-0,04$ & $--\quad-$ & 0,00 & $-0,37$ \\
\hline ESCOLA & -- & 0,25 & 0,10 & $--\quad-$ & $-0,01$ & 0,00 \\
\hline
\end{tabular}

O modelo, que se ajusta muito bem aos dados, mostra que os dados observados são compatíveis com a seguinte estrutura e seqüência de relacionamento entre os fatores: a família conquista primeiro os recursos econômicos; a seguir, com as possibilidades geradas por esta situação, algumas famílias adquirem bens culturais; tendo estas duas condições, dedicam tempo para acompanhar a vida escolar de seus filhos. Em particular, escolhem uma escola para seus filhos onde eles encontram colegas de famílias semelhantes. Além disso, refletindo o ambiente favorável da casa, os estudantes desenvolvem melhor atitude em relação à escola. Tudo isto resulta em maior proficiência em matemática. Por outro lado, os alunos defasados em sua trajetória escolar são filhos de fa- 
mílias com recursos econômicos mais baixos e, além disso, por estar nesta situação, não recebem muita atenção de seus pais, conjugação de fatores que se reflete em graus ainda menores de desempenho.

\section{DISCUSSÃO}

Os resultados deste artigo mostram que a análise de dados de surveys educacionais deve considerar a influência familiar não através de um único índice síntese de posição social, mas de dois fatores, um medindo os recursos econômicos e outro os recursos culturais da família dos estudantes. Os indicadores de escolaridade dos pais devem compor a medida do fator "recursos culturais na residência". Devido ao grande número de alunos incluídos na amostra e também à quantidade dos itens do questionário contextual, é possível, com os dados do Saeb, medir separadamente o fator cultural e o fator econômico. Estes itens, entretanto, não cobrem toda a variedade possível de atitudes de valorização de atividades intelectuais de uma família. Esta é uma área na qual aperfeiçoamentos são possíveis e desejáveis.

Dentre todos os construtos considerados, aqueles que apresentam a associação mais forte entre si são os fatores cultural e econômico da família. Esta constatação corrobora o poder explicativo da teoria da reprodução social de Pierre Bourdieu para o caso do ensino básico brasileiro. De acordo com a teoria de Bourdieu, famílias com mais recursos econômicos adquirem mais recursos culturais e proporcionam a seus filhos maiores oportunidades de, através do sucesso escolar, manter ou elevar o seu status socioeconômico. A evidência obtida não é, entretanto, determinística. Há variação em torno dessa estrutura de reprodução. Ela não acontece para todos os estudantes nem na mesma intensidade. O PISA mostrou que, mesmo na presença de grande igualdade econômica, se observam grandes diferenças de desempenho entre estudantes. Ou seja, a associação entre os fatores econômico e cultural e seu impacto conjunto no desempenho escolar não é um componente estrutural de qualquer sociedade, mas uma característica da atual organização social brasileira. Outra possível explicação para esta alta associação, que não pode ser descartada, é a de que os indicadores usados, quase todos associados à presença de bens na residência do aluno, não descrevem adequadamente o fator recursos culturais. Itens que captassem a valorização de atividades culturais pela família e que não dependessem da posse de bens deveriam ser agregados a estes questionários. 
Os resultados das seções anteriores mostram que os dados do Saeb são compatíveis tanto com a hipótese de efeitos indiretos dos recursos econômicos quanto com a do envolvimento dos pais no desempenho cognitivo dos estudantes. É importante lembrar que o resultado final que se quer explicar neste estudo é a proficiência em matemática de alunos da oitava série do ensino fundamental. Se utilizássemos a renda que o estudante terá na idade adulta como variável resposta, certamente outros fatores familiares poderiam ter um impacto maior do que o da dimensão cultural. O chamado modelo de Wisconsin de sucesso econômico introduzido por Sewell, Haller e Portes (1969), por exemplo, que tem como variável resposta final a ocupação profissional do indivíduo, inclui efeitos indiretos da estrutura familiar através de fatores como as expectativas educacionais e ocupacionais dos alunos e a influência dos colegas e professores no desempenho econômico futuro do indivíduo.

Deve-se destacar de forma especial que o modelo final atribui um papel de ativação dos recursos culturais ao envolvimento dos pais com a educação de seus filhos. Segundo essa análise, passa por esta atitude dos pais a possibilidade de concretização, em termos de desempenho dos alunos, daquilo que foi obtido pela família em termos de recursos econômicos e culturais.

No entanto, de forma mais incisiva, as análises anteriores mostram que, naturalmente, as famílias procuram colocar seus filhos em escolas que retratem os seus valores culturais. A conseqüência disso é a formação de comunidades escolares completamente segregadas em termos da facilidade de execução do processo de ensino-aprendizagem. Tal divisão favorece os filhos de famílias com valores mais altos no indicador de recursos culturais, que vão dividir o espaço de sua escola com colegas cujas famílias possuem recursos semelhantes. Esse processo é restringido, para as famílias que matriculam seus filhos na escola pública, pelas políticas de alocação de alunos por área residencial. As famílias que usam as escolas particulares, por sua vez, não sofrem nenhuma restrição desse tipo e podem se agrupar mais facilmente. Como o ambiente escolar é forte determinante, através do efeito dos pares, do desempenho acadêmico, os alunos das famílias com recursos financeiros limitados, mas com alto capital cultural, são prejudicados.

Diante destes resultados, surge a questão sobre como a escola típica pode, através de parcerias com as famílias, potencializar o seu efeito educativo. $\mathrm{O}$ modelo final sugere que isto se deve dar através da cria- 
ção, em todas as escolas, do mesmo ambiente que é criado, naturalmente, pela presença de alunos de mais recursos econômicos e melhores atitudes intelectuais. O trabalho para atingir este objetivo começa com as famílias criando ambientes familiares que apóiem e encorajem o aprendizado de seus filhos. Ou seja, o que se espera da família é a expressão, através de ações concretas, de que o trabalho escolar é importante, e não que a família assuma o papel da escola, dedicando-se a ensinar os conteúdos escolares a seus filhos. Concomitante a estas atitudes, a família deve expressar expectativas altas, mas não irreais, sobre o desempenho acadêmico de seus filhos na escola e em suas carreiras futuras. Mas os dados são claros em demonstrar que os efeitos destas atitudes serão muito mais fortes se ocorrerem no conjunto dos alunos da escola e não apenas em alguns alunos. Daí a importância do envolvimento de toda a comunidade servida pela escola. A possibilidade de efeitos no desempenho dos alunos por esta via é tão forte que a busca de uma maior integração escola-família deve ser parte do projeto da escola.

A transformação ao longo das linhas aqui sugeridas é tarefa muito difícil, principalmente em comunidades em que as famílias têm pouco capital cultural ou pouca capacidade de organização. Isto se explica, às vezes, pela dificuldade de entendimento e participação dos pais dos alunos em uma estrutura da qual não dominam a linguagem e com a qual eles próprios tiveram pouco contato ou, ainda, um contato negativo. Além disso, muitos pais consideram a escola uma estrutura meramente profissional e não se vêem com as habilidades necessárias para intervir diretamente na rotina desta. Finalmente, cabe registrar que, em escolas que atendem alunos com altos níveis de pobreza, este projeto é quase impossível, e a ação necessária talvez seja de natureza mais econômica no sentido de prover o acesso das famílias a bens básicos.

As análises apresentadas mostram um quadro complexo de relação entre as características das famílias, da escola e o desempenho dos alunos. Certamente, entretanto, os dados do Saeb indicam que o efeito da família não é menor do que o da escola, mesmo em contextos onde faltam recursos básicos à escola, como defendido por Heyneman e Loxley (1983). Também Baker, Goesling e Letendre (2002), em um contexto mais geral, encontraram evidências de que hoje, no mundo, o efeito das famílias no desempenho acadêmico de seus filhos é dominante. $\mathrm{Na}$ realidade, o que a análise cuidadosa dos dados mostra é a necessidade de ação conjunta destas duas estruturas sociais para que haja melhori- 
as substanciais tanto no nível quanto na equidade educacional. Infelizmente, até muito recentemente, técnicos de agências internacionais influenciaram na adoção de políticas públicas que colocam mais esperança e pressão na ação isolada que a escola pode exercer no desempenho dos alunos do que a evidência encontrada nos dados sugere ser factível. Estas políticas levam mais à frustração do que à produção de efeitos.

Ressaltamos que o modelo estatístico de análise dos dados utilizado neste artigo é constituído de seis equações de regressão simultâneas. Como há associação entre as equações, os parâmetros das diferentes equações devem ser estimados de forma conjunta. No entanto, a primeira equação, cuja resposta é a proficiência dos alunos, deve considerar que alunos de uma mesma escola se influenciam mutuamente. Isto indica como melhor forma de estimação uma regressão hierárquica. Para a estimativa conjunta das equações, contudo, a dependência da variação dos resultados dos alunos em relação à escola em que estão inseridos não pode ser considerada. Apesar disso, a semelhança entre os coeficientes dos resultados da primeira equação e os do ajuste do modelo de regressão hierárquica mostra que o modelo de análise de trajetória aqui apresentado não é viciado. O modelo obtido, embora substantivamente razoável, deve ser verificado em outras situações. O próprio Saeb fornece várias oportunidades para isto, trabalho que será feito eventualmente. De forma especial, deve-se procurar verificar como a inclusão de outros itens no questionário contextual respondido pelo aluno para a construção da medida do fator "recursos culturais na residência" afeta os resultados obtidos.

(Recebido para publicação em agosto de 2005)

(Versão definitiva em setembro de 2006) 


\section{NOTA}

1. Survey realizado pela Organization for Economic Cooperation and Development OECD, com estudantes de 15 anos de diversos países. O PISA possui uma estrutura semelhante a do Saeb, aliando questionários contextuais a resultados de testes em matemática, leitura e ciências.

\section{REFERÊNCIAS BIBLIOGRÁFICAS}

ANDRADE, D., SILVA, P. L. N. e BUSSAB, W. O. (2001), O Plano Amostral para o SAEB 2001. Brasília, INEP/MEC (versão final).

BAKER, D. P., GOESLING, B. e LETENDRE, G. (2002), "Socioeconomic Status, School Quality, and National Economic Development: A Cross-national Analysis of the 'Heyneman-Loxley Effect' on Mathematics and Science Achievement'. Comparative Education Review, vol. 46, no 3, pp. 291-312.

BARTHOLOMEW, D. J. (2002), The Analysis and Interpretation of Multivariate Data for Social Scientists. Flórida, Chapman \& Hall/CRC.

e KNOTT, M. (1999), Latent Variable Models and Factor Analysis. London/New York, Arnold/Oxford University Press.

BOURDIEU, P. e PASSERON, J. C. (1964), Les Héritiers. Les Étudiants et la Culture. Paris, Minuit.

BRESSOUX, P. (1994), “Les Recherches sur les Effets-Écoles et les Effets-Maîtres”. Revue Française de Pédagogie, no 108, pp. 91-137.

BUCHMANN, C. e DALTON, B. (2002), "Interpersonal Influences and Educational Aspirations in 12 Countries: The Importance of Institutional Context". Sociology of Education, vol. 75, no 2, pp. 99-122.

COLEMAN, J. S. (1988), "Social Capital in the Creation of Human-Capital". American Journal of Sociology, no 94, pp. 95-120.

COLEMAN, J. S. et alii. (1966), Equality of Educational Opportunity. Washington, D. C., US Government Printing Office.

CRESPO, M., SOARES, J. F. e SOUZA, A. M. (2000), “The Brazilian Evaluation System of Basic Education: Context, Process and Impact". Studies in Educational Evaluation, no 20, pp. 105-125.

DE GRAAF, N. D. e DE GRAAF, P. M. (2000), “Parental Cultural Capital and Educational Attainment in the Netherlands: A Refinement of the Cultural Capital Perspective". Sociology of Education, vol. 73, no 2, pp. 92-111. 
DiMAGGIO, P. (1982), "Cultural Capital and School Success - The Impact of Status Culture Participation on the Grades of United-States High-School-Students". American Sociological Review, vol. 47, no 2, pp. 189-201.

FORQUIN, J. C. (1995), Sociologia da Educação: Dez Anos de Pesquisas. Petrópolis, Editora Vozes.

FRANCO, C. (org.). (2001a), Promoção, Ciclos e Avaliação Educacional. Porto Alegre, ArtMed.

. (2001b), “O SAEB: Potencialidades, Problemas e Desafios". Revista Brasileira de Educação, no 17, pp. 127-132.

GANZEBOOM, H. B. G. e TREIMAN, D. J. (1996), “Internationally Comparable Measures of Occupational Status for the 1988 International Standard Classification of Occupations". Social Science Research, vol. 25, no 3, pp. 201-239.

GARIB, G., GARCIA, T. Martin e DRONKERS, J. (2003), “Are the Effects of Different Family-forms on Children's Educational Performance Related to the Demographic Characteristics and Family Policies of Modern Societies?". Disponível em http:/ / www.iue.it/Personal/Dronkers/English/divorcePISA.pdf (acessado em $31 / 7 / 2005)$.

GOLDSTEIN, H. (2003), Multilevel Statistical Models. London, E. Arnold.

HANUSCHEK, E.A., KAIN, J. F., MARKMAN, J. M. e RIVKIN, S. G. (2003), “Does Peer Ability Affect Student Achievement". Journal of Applied Economics, vol. 18, no 5, pp. 527-544.

HAYDUK, L A. (1987), Structural Equation Modeling with LISREL: Essentials and Advances. London, The Johns Hopkins University Press.

HEYNEMAN, S. P. e LOXLEY, W. A. (1983), "The Effect of Primary-School Quality on Academic-Achievement across 29 High-Income and Low-Income Countries". American Journal of Sociology, vol. 88, no 6, pp. 1.162-1.194.

INSTITUTO NACIONAL DE ESTUDOS E PESQUISAS EDUCACIONAIS - Inep. (2001), Saeb 2001: Novas Perspectivas. Brasília. Disponível em http://www.inep.gov.br/basica/saeb/publicacoes.htm (acessado em julho de 2005).

KLEIN, R. e FONTANIVE, N. S. (1995), “Avaliação em Larga Escala: Uma Proposta Inovadora". Em Aberto, no 66, pp. 29-35.

LAREAU, A. (1989), Home Advantage: Social Class and Parental Intervention in Elementary Education. Philadelphia, Falmer.

LAREAU, A. e WEININGER, E. B. (2003), "Cultural Capital in Educational Research: A Critical Assessment". Theory and Society, vol. 32, no 5-6, pp. 567-606.

LEE, V. E. (2000), “Using Hierarchical Linear Modeling to Study Social Contexts: The Case of School Effects". Educational Psychologist, no 35, pp. 125-141.

LOCATELLI, I. (2002), “Construção de Instrumentos para a Avaliação de Larga Escala e Indicadores de Rendimento: O Modelo SAEB". Estudos em Avaliação Educacional, 25, pp. 3-21. 
MALUF, M. M. B. (1996), "Sistema Nacional de Avaliação da Educação Básica no Brasil: Análise e Proposições". Estudos em Avaliação Educacional, no 14, pp. 5-38.

MOSTELLER, F. e MOYNIHAN, D. P. (1972), On Equality of Educational Opportunity. New York, Random House.

NOGUEIRA, M. A. (1990), “A Sociologia da Educação do Final dos Anos 60/Início dos Anos 70: O Nascimento do Paradigma da Reprodução". Em Aberto, vol. 9, no 46, pp. 49-59.

PUTNAM, Robert. (1993), Making Democracy Work: Civic Traditions in Modern Italy. Princeton, Princeton University Press.

RAUDENBUSH, S. W. e BRYK, A. S. (2002), Hierarchical Linear Models: Applications and Data Analysis Methods. Thousand Oaks, Sage Publications.

SEWELL, W. H., HALLER, A. O. e PORTES, A. (1969), “Educational and Early Occupational Attainment Process". American Sociological Review, vol. 34, no 1, pp. 82-92.

SOARES, J. F. (2003), "Quality and Equity in Brazilian Basic Education: Facts and Possibilities", in S. Schwartzman e C. Brock (eds.), In The Challenges of Education in Brasil. Oxford, Center for Brazilian Studies, University of Oxford, pp. 69-88.

e ALVES, M. T. G. (2003), “Desigualdades Raciais no Sistema Brasileiro de Educação Básica". Revista da Faculdade de Educação, vol. 29, pp. 147-165.

SOARES, J. F., CÉSAR, C. C. e MAMBRINI, J. (2001), “Determinantes de Desempenho dos Alunos do Ensino Básico Brasileiro: Evidências do SAEB de 1997", in C. Franco (org.), Promoção, Ciclos e Avaliação Educacional. Porto Alegre, ArtMed Editora, pp. 121-153.

SOARES, T. M. (2003), "Influência do Professor e do Ambiente em Sala de Aula sobre a Proficiência Alcançada pelos Alunos Avaliados no Simave-2002". Estudos em Avaliação Educacional, no 28, pp. 103-123.

WILLMS, J. D. (1992), Monitoring School Performance: A Guide for Educators. Washington, Falmer. 


\section{APÊNDICE}

\section{MEDIDAS DOS FATORES}

Todos os fatores explicativos incluídos nas análises apresentadas nas seções anteriores foram medidos por indicadores ordinais, obtidos através de itens presentes nos questionários dos alunos no Saeb. Embora a análise tenha se restringido aos alunos de escolas públicas, a medida de todos os fatores foi feita usando os 50.300 alunos testados na oitava série em matemática no Saeb 2001. Isto evita a criação de diferenças artificiais nos valores das medidas e permite um teste mais rigoroso das associações entre as variáveis consideradas. O processo de construção da medida do fator consistiu primeiro na produção, através do software LISREL, e análise da matriz de correlação policórica entre os indicadores. Esta matriz deveria possuir apenas valores positivos e seu maior autovalor deveria ser amplamente dominante. Apresentamos a seguir todos os autovalores e autovetores maiores do que 1. Em uma segunda etapa, a medida do fator é obtida como subproduto do ajuste do modelo TRI para dados ordinais, introduzido por Samejima e implementado no software MULTILOG e descrito, por exemplo, em Bartholomew (2002) e Bartholomew e Knott (1999).

\section{ENVOLVIMENTO DOS PAIS: PAIS}

Os itens 7 a 19 do questionário 2 do Saeb respondido pelo aluno foram considerados para a construção da medida de capital social. Embora potencialmente úteis para a medida de capital social, os itens 14 e 15 do questionário, que tratam da freqüência de conversa entre os pais dos alunos com os amigos dos filhos e respectivos pais, não se relacionaram de forma consistente com os 11 itens incluídos e, portanto, não foram utilizados na construção da escala. Todos os itens incluídos têm a seguinte redação geral: Em geral, com que freqüência seus pais ou os responsáveis que moram com você: [Nunca, raramente, Quase sempre, Sempre]

$\begin{array}{lll}\text { 1. } & \text { Conversam com você sobre livros? } & \text { COLIVROS } \\ 2 . & \text { Conversam com você sobre filmes? } & \text { COFILMES } \\ \text { 3. } & \text { Conversam com você sobre programas de TV? } & \text { COPROGTV } \\ 4 . & \text { Conversam com você sobre outros assuntos? } & \text { COOUROS } \\ 5 . & \text { Ouvem música com você? } & \text { MUSICA } \\ 6 . & \text { Almoçam ou jantam com você? } & \text { ALMOCA } \\ 7 . & \text { Conversam com você sobre o que acontece na escola? } & \text { COESCOLA }\end{array}$


8. Ajudam você a fazer a lição de casa?

FALICAO

9. $\quad$ Cobram se você fez a lição de casa?

COLICAO

10. Procuram fazer com que você não chegue atrasado à escola? ATRASAD

11. Incentivam você a tirar boas notas na escola?

BOANOTAS

$\mathrm{O}$ indicador de envolvimento dos pais foi construído utilizando-se a resposta dos alunos aos 11 itens apresentados anteriormente e capta o grau de participação dos pais, seja na rotina diária, seja no acompanhamento da vida escolar de seus filhos.

O Quadro 1.1 apresenta a matriz de correlação policórica. Observe-se que todas as correlações são positivas.

Quadro 1.1

Matriz de Correlação Policórica - Envolvimento dos Pais

\begin{tabular}{|c|c|c|c|c|c|c|c|c|c|c|c|}
\hline & COLIVRos & COFILMES & COPROGTV & COOUTROS & MUSICA & ALMOCA & COESCOLA & FALICAO & COLICAO & ATRASAD & BOANOTAS \\
\hline COLIVROS & 1,00 & & & & & & & & & & \\
\hline COFILMES & 0,47 & 1,00 & & & & & & & & & \\
\hline COPROGTV & 0,39 & 0,67 & 1,00 & & & & & & & & \\
\hline COOUTROS & 0,33 & 0,41 & 0,44 & 1,00 & & & & & & & \\
\hline MUSICA & 0,27 & 0,34 & 0,35 & 0,34 & 1,00 & & & & & & \\
\hline ALMOCA & 0,23 & 0,20 & 0,26 & 0,33 & 0,27 & 1,00 & & & & & \\
\hline COESCOLA & 0,50 & 0,38 & 0,42 & 0,46 & 0,30 & 0,31 & 1,00 & & & & \\
\hline FALICAO & 0,41 & 0,28 & 0,26 & 0,22 & 0,27 & 0,24 & 0,39 & 1,00 & & & \\
\hline COLICAO & 0,39 & 0,23 & 0,24 & 0,23 & 0,20 & 0,28 & 0,49 & 0,49 & 1,00 & & \\
\hline ATRASAD & 0,31 & 0,23 & 0,26 & 0,29 & 0,20 & 0,34 & 0,41 & 0,32 & 0,52 & 1,00 & \\
\hline BOANOTAS & 0,38 & 0,28 & 0,31 & 0,38 & 0,26 & 0,38 & 0,51 & 0,37 & 0,55 & 0,62 & 1,00 \\
\hline
\end{tabular}

Os autovalores maiores do que 1, com os respectivos autovetores, são apresentados nos Quadros 1.2 e 1.3. O primeiro fator é uma síntese dos 11 itens; o segundo contrasta a interação pais/filhos de fundo escolar com a interação mais rotineira. Considerando o tamanho dos respectivos autovalores, optamos por construir apenas um fator com estes itens.

Entre todos os itens incluídos, aquele referente à freqüência de conversas entre pais e filhos sobre o que acontece na escola é o que fornece mais informação sobre o fator. A Figura 1.2 mostra o histograma da medida de envolvimento dos pais obtida com o procedimento descrito.

O histograma mostra um pequeno número de alunos com valores nos dois extremos da escala. Há 206 alunos que responderam a todos os 11 itens com o valor mais alto da escala e 163 que utilizaram apenas o me- 
Quadro 1.2

Autovetores - Envolvimento dos Pais

\begin{tabular}{|c|c|c|c|c|c|}
\hline Itens & Fator1 & Fator2 & Itens & Fator1 & Fator2 \\
\hline COLIVROS & 0,315 & 0,083 & COESCOLA & 0,352 & $-0,036$ \\
\hline COFILMES & 0,298 & 0,471 & FALICAO & 0,283 & $-0,182$ \\
\hline COPROGTV & 0,306 & 0,444 & COLICAO & 0,313 & $-0,401$ \\
\hline COOUTROS & 0,294 & 0,242 & ATRASAD & 0,303 & $-0,376$ \\
\hline MUSICA & 0,243 & 0,263 & BOANOTAS & 0,343 & $-0,313$ \\
\hline ALMOCA & 0,247 & $-0,108$ & & & \\
\hline
\end{tabular}

Quadro 1.3

Autovalores - Envolvimento dos Pais

\begin{tabular}{|l|c|c|}
\hline & Fator1 & Fator2 \\
\hline Autovalores & 4,53 & 1,37 \\
\hline \% Variância & 41,17 & 12,46 \\
\hline \% Var. Acumulada. & 41,17 & 53,63 \\
\hline
\end{tabular}

Figura A1

Histograma do Fator Envolvimento dos Pais

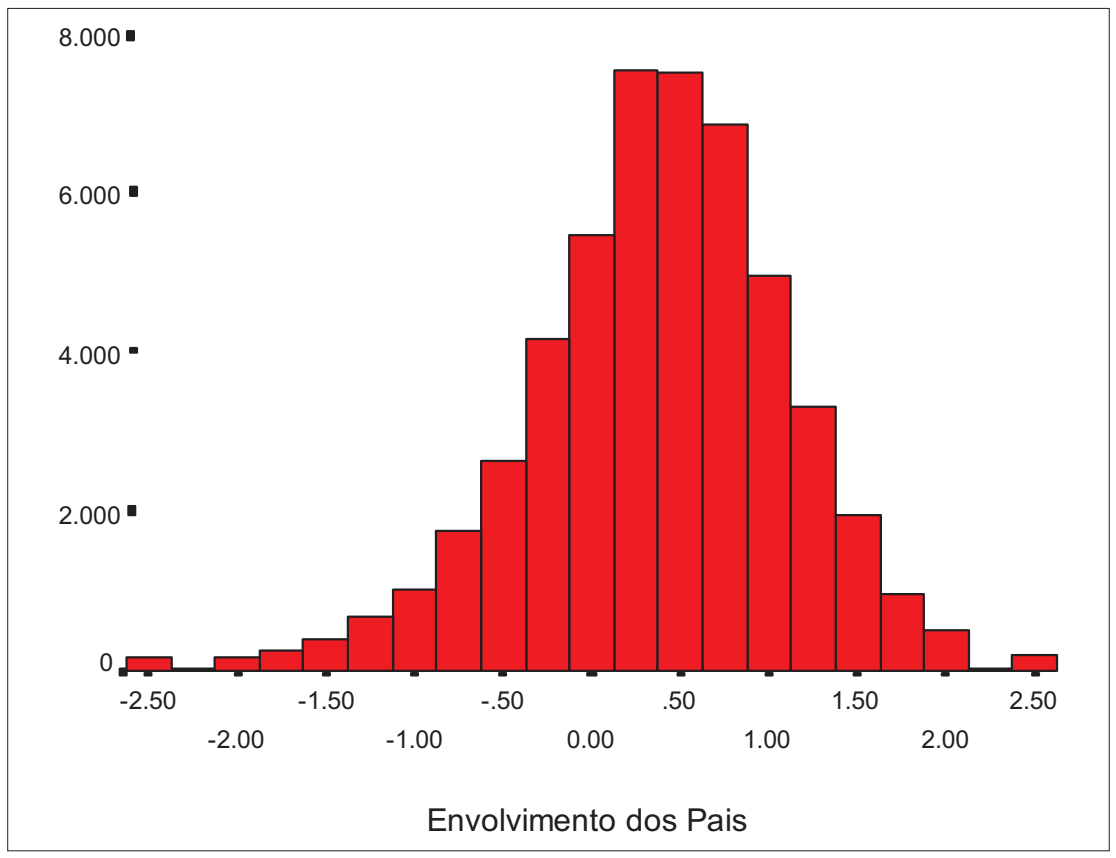


nor valor. Como se pode ver no histograma, estes alunos estão isolados em relação aos outros, fruto do comportamento extremo e suspeito. Estes dados podem ser o resultado de preenchimento descompromissado, mas na ausência de informação que possa validar esta hipótese e considerando o grande número de alunos na amostra optamos por manter todos os alunos nas análises subseqüentes.

\section{Recursos Culturais: CULTURAL}

Onze itens foram utilizados para a construção do fator recursos culturais. Dentre eles, dois investigam a escolaridade dos responsáveis pelos alunos, enquanto os demais apresentam uma caracterização do ambiente residencial do aluno como apropriado ou não para o aprendizado. Com exceção dos itens sobre escolaridade dos responsáveis e o que investiga a quantidade de livros existentes na casa do aluno, os outros itens têm a seguinte redação geral: Há em sua casa:

1. Até que série a responsável por você estudou?

SERIEMAE

2. Até que série o responsável por você estudou? SERIEPAI

3. Quantos livros existem na casa do aluno além dos livros escolares?

LIVROS

4. Um lugar calmo para você estudar e fazer o dever de casa?

LUGCALMO

5. Um jornal diário?

JORNAL

6. Revistas de informação geral?

REVISTA

7. Uma enciclopédia?

ENCICLOP

8. Um atlas?

ATLAS

9. Um dicionário?

DICION

10. Uma calculadora?

CALCUL

11. Acesso à internet?

INTERNET

A matriz de correlação é apresentada no Quadro 2.1. Observe-se que todas as correlações são positivas.

Os autovalores correspondentes a autovetores maiores do que 1 são apresentados nos Quadros 2.2 e 2.3. O primeiro fator é uma síntese dos 11 itens; o segundo contrasta a escolaridade dos responsáveis e a existência de acesso à internet com a presença dos seguintes itens: lugar calmo para estudar, enciclopédia, atlas, dicionário e calculadora. Considerando o tamanho dos respectivos autovalores, construímos apenas um fator com estes itens. 
Quadro 2.1

Matriz de Correlação Policórica - Recursos Culturais

\begin{tabular}{|l|c|c|c|c|c|c|c|c|l|l|l|}
\hline SERIEMAE & $\begin{array}{c}\text { SERIEMAE } \\
1,00\end{array}$ & SERIEPAI & LIVROS & LUGCALMo & JORNAL & REVISTA & ENCICLOP & ATLAS & Dicion & CALCUL & INTERNET \\
\hline SERIEPAI & 0,64 & 1,00 & & & & & & & & & \\
\hline LIVROS & 0,46 & 0,42 & 1,00 & & & & & & & & \\
\hline LUGCALMO & 0,21 & 0,20 & 0,25 & 1,00 & & & & & & & \\
\hline JORNAL & 0,26 & 0,29 & 0,30 & 0,18 & 1,00 & & & & & & \\
\hline REVISTA & 0,34 & 0,32 & 0,41 & 0,23 & 0,42 & 1,00 & & & & & \\
\hline ENCICLOP & 0,41 & 0,39 & 0,54 & 0,25 & 0,33 & 0,38 & 1,00 & & & & \\
\hline ATLAS & 0,36 & 0,34 & 0,50 & 0,21 & 0,32 & 0,36 & 0,62 & 1,00 & & & \\
\hline DICION & 0,36 & 0,32 & 0,49 & 0,24 & 0,29 & 0,36 & 0,54 & 0,52 & 1,00 & & \\
\hline CALCUL & 0,31 & 0,30 & 0,36 & 0,27 & 0,27 & 0,30 & 0,36 & 0,38 & 0,54 & 1,00 & \\
\hline INTERNET & 0,52 & 0,54 & 0,52 & 0,28 & 0,44 & 0,48 & 0,54 & 0,49 & 0,46 & 0,41 & 1,00 \\
\hline
\end{tabular}

Quadro 2.2

Autovetores - Recursos Culturais

\begin{tabular}{|l|c|c|l|c|c|}
\hline \multicolumn{1}{|c|}{ Itens } & Fator1 & Fator2 & \multicolumn{1}{|c|}{ Itens } & Fator1 & Fator2 \\
\hline SERIEMAE & 0,305 & 0,523 & ENCICLOP & 0,341 & $-0,179$ \\
\hline SERIEPAI & 0,299 & 0,565 & ATLAS & 0,324 & $-0,26$ \\
\hline LIVROS & 0,332 & $-0,018$ & DICION & 0,323 & $-0,364$ \\
\hline LUGCALMO & 0,186 & $-0,184$ & CALCUL & 0,277 & $-0,338$ \\
\hline JORNAL & 0,248 & 0,023 & INTERNET & 0,359 & 0,162 \\
\hline REVISTA & 0,283 & 0,014 & & & \\
\hline
\end{tabular}

Quadro 2.3

Autovalores - Recursos Culturais

\begin{tabular}{|l|c|c|}
\hline & Fator1 & Fator2 \\
\hline Autovalores & 4,88 & 1,02 \\
\hline \% Variância & 44,41 & 9,27 \\
\hline \% Var. Acumulada. & 44,41 & 53,68 \\
\hline
\end{tabular}

O histograma a seguir ilustra o resultado obtido.

\section{Recursos Econômicos: ECONO}

Treze itens foram utilizados para a construção do fator capital econômico. Dentre eles, 10 são referentes a itens de posse existentes na residência do aluno; os outros são: a existência de empregada doméstica, se o aluno trabalha e o número de pessoas que moram com o aluno. Nos itens de posse e em relação à empregada doméstica, é registrada a 
Figura A 2

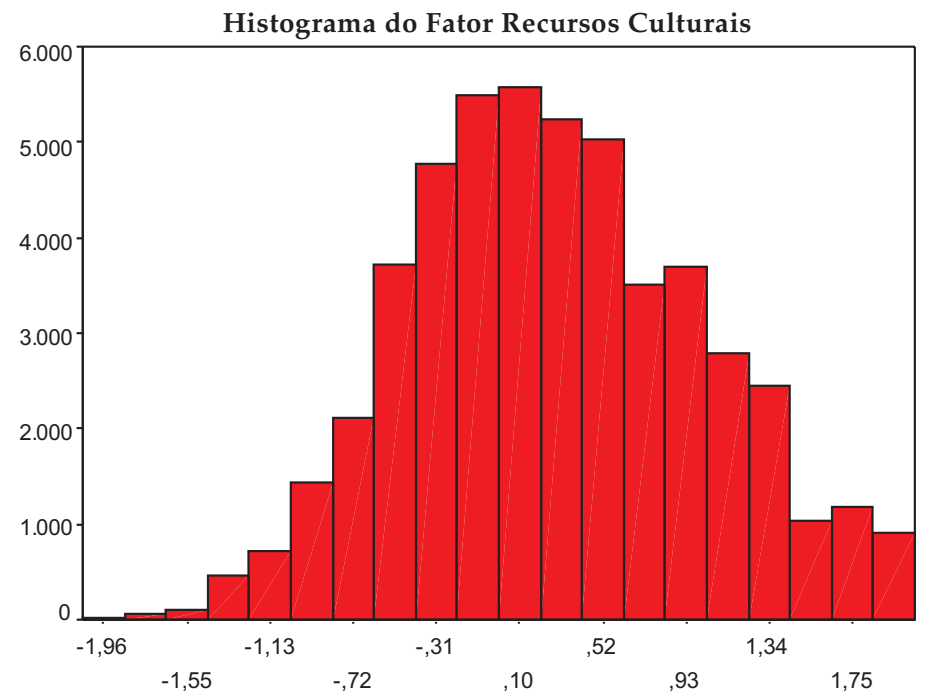

Recursos Culturais

quantidade. $\mathrm{O}$ fato de o aluno trabalhar é medido através de uma variável dicotômica (trabalha/não trabalha).

1. Você trabalha?

TRAB

2. Quantidade de empregadas domésticas em sua casa

DOMESTIC

3. Quantos banheiros há no lugar onde você mora?

BANHEIR

4. Quantos rádios há no lugar onde você mora?

RADIO

5. Quantas televisões em cores há no lugar onde você mora?

TVCORES

6. Quantos videocassetes há no lugar onde você mora?

VIDEOS

7. Quantas geladeiras há no lugar onde você mora?

GELAD

8. Quantos freezers há no lugar onde você mora?

FREEZER

9. Quantas máquinas de lavar roupa há no lugar onde você mora? MAQLAVAR

10. Quantos aspiradores de pó há no lugar onde você mora?

ASPIRAPO

11. Quantos computadores há no lugar onde você mora?

COMPUT

12. Quantos automóveis há no lugar onde você mora?

AUTOMOV

13. Número de pessoas por quarto na sua residência

PESSOA

A matriz de correlação policórica é apresentada no Quadro 3.1. Observe-se que todas as correlações são positivas. 
Quadro 3.1

Matriz de Correlação Policórica - Recursos Econômicos

\begin{tabular}{|l|c|c|c|c|c|c|c|c|c|c|c|c|c|}
\hline & TRAB & DOMESTIC & BANHEIR & RADIO & TVCORES & VIDEO & GELAD & FREEZER & MAQLAVAR & ASPIRAPO & COMPUT & AUTOMOV & PESSOA \\
\hline TRAB & 1,00 & & & & & & & & & & & & \\
\hline DOMESTIC & 0,20 & 1,00 & & & & & & & & & & & \\
\hline BANHEIR & 0,25 & 0,62 & 1,00 & & & & & & & & & & \\
\hline RADIO & 0,19 & 0,40 & 0,48 & 1,00 & & & & & & & & & \\
\hline TVCORES & 0,31 & 0,54 & 0,62 & 0,59 & 1,00 & & & & & & & & \\
\hline VIDEO & 0,27 & 0,54 & 0,58 & 0,56 & 0,73 & 1,00 & & & & & & & \\
\hline GELAD & 0,16 & 0,38 & 0,48 & 0,40 & 0,55 & 0,46 & 1,00 & & & & & & \\
\hline FREEZER & 0,15 & 0,49 & 0,52 & 0,42 & 0,55 & 0,53 & 0,36 & 1,00 & & & & & \\
\hline MAQLAVAR & 0,13 & 0,31 & 0,40 & 0,36 & 0,47 & 0,48 & 0,44 & 0,48 & 1,00 & & & & \\
\hline ASPIRAPO & 0,21 & 0,43 & 0,51 & 0,53 & 0,60 & 0,63 & 0,41 & 0,52 & 0,54 & 1,00 & & & \\
\hline COMPUT & 0,30 & 0,63 & 0,64 & 0,55 & 0,68 & 0,71 & 0,44 & 0,56 & 0,50 & 0,67 & 1,00 & & \\
\hline AUTOMOV & 0,21 & 0,61 & 0,62 & 0,48 & 0,61 & 0,62 & 0,45 & 0,56 & 0,48 & 0,60 & 0,71 & 1,00 & \\
\hline PESSOA & 0,14 & 0,35 & 0,47 & 0,30 & 0,35 & 0,33 & 0,25 & 0,30 & 0,25 & 0,34 & 0,41 & 0,36 & 1,00 \\
\hline
\end{tabular}

Apenas um autovalor maior do que 1 . Seu valor é 6,6, com capacidade explicativa da variância de $51,20 \%$. Seu respectivo autovetor é apresentado no Quadro 3.2. Trata-se de uma síntese dos 13 itens.

Quadro 3.2

Autovetor - Recursos Econômicos

\begin{tabular}{|l|c|l|c|}
\hline \multicolumn{1}{|c|}{ Itens } & Fator1 & \multicolumn{1}{c|}{ Itens } & Fator1 \\
\hline TRAB & 0,130 & FREEZER & 0,275 \\
\hline DOMESTIC & 0,278 & MAQLAVAR & 0,247 \\
\hline BANHEIR & 0,306 & ASPIRAPO & 0,300 \\
\hline RADIO & 0,266 & COMPUT & 0,334 \\
\hline TVCORES & 0,324 & AUTOMOV & 0,314 \\
\hline VIDEO & 0,319 & PESSOA & 0,196 \\
\hline GELAD & 0,242 & & \\
\hline
\end{tabular}

O histograma a seguir ilustra o resultado obtido.

\section{ATRASO ESCOLAR}

Este fator é medido pela diferença, em anos, entre a idade e a idade típica para a série em que o aluno se encontra. Apesar de exigir apenas o conhecimento da data de nascimento, a informação está faltando para 2.696 alunos das escolas públicas. Entre os alunos com dados completos há uma clara associação entre o atraso escolar e o sexo, a raça e a condição econômica. Diante disto, optamos por imputar o atraso escolar usando o percentil de ordem 75 dos alunos com dados completos e 
Figura A 3

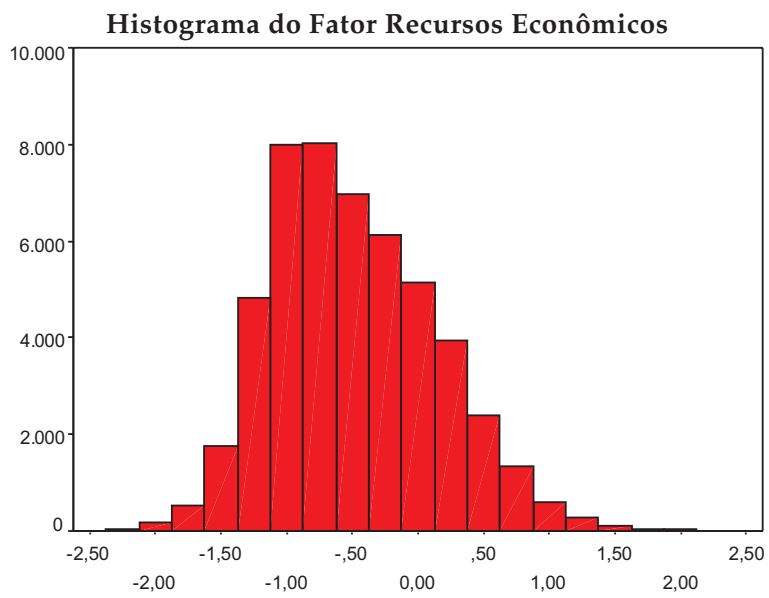

Recursos Econômicos

pertencentes à mesma casela, definida pelas variáveis sexo, raça e fator econômico, discretizada em três categorias. A escolha do percentil 75 é baseada no entendimento de que a própria ausência da informação também sugere maior atraso escolar. O Quadro 3.3 mostra os valores imputados em cada casela. Após esta imputação, eliminamos os alunos sem informação de raça ou sexo.

Quadro 3.3

Valores Usados para Imputação do Atraso Escolar

\begin{tabular}{|c|c|c|c|}
\hline Sexo & Raça & Classe & Atraso Imputado \\
\hline 0 & 0 & 1 & 2 \\
0 & 0 & 2 & 2 \\
0 & 0 & 3 & 3 \\
0 & 1 & 1 & 1 \\
0 & 1 & 2 & 2 \\
0 & 1 & 3 & 3 \\
1 & 0 & 1 & 2 \\
1 & 0 & 2 & 2 \\
1 & 0 & 3 & 3 \\
1 & 1 & 1 & 1 \\
1 & 1 & 2 & 1 \\
1 & 1 & 3 & 3 \\
\hline
\end{tabular}




\begin{abstract}
Family Resources and Cognitive Performance by Primary School Students in Brazil

This article discusses the processes by which family structure affects students' cognitive performance in Brazilian schools. The article's basic premise is that family influence is not a uni-dimensional construct, and the study thus uses four dimensions to capture such influence. The effects of these factors on students' performance are measured through a school attainment analysis model. The data are compatible with a model in which the parents' involvement acts as a mediating factor for the action of cultural resources, which in turn depend on economic resources, which have only indirect effects on students' cognitive performance in primary school.
\end{abstract}

Key words: scholastic performance; family effect; school effect

\title{
RÉSUMÉ
}

Ressources des Familles et Performance Cognitive des Élèves de l'Enseignement Primaire et Secondaire au Brésil

Dans cet article, on examine les processus à travers lesquels la structure familiale peut gêner les performances cognitives des élèves au Brésil. On part du pressupposé que l'influence de la famille ne repose pas sur un principe unidimensionnel mais que, pour la saisir, il faut se servir de quatre dimensions. Les effets de ces facteurs sur les résultats scolaires des élèves sont examinés par le moyen d'un modèle d'analyse des trajectoires. Les données sont compatibles avec un modèle où l'engagement des parents agit comme un facteur de médiation dans l'intervention des ressources culturelles qui, à leur tour, dépendent des ressources économiques; celles-ci n'ont que des effets indirects sur les performances cognitives des élèves de l'enseignement primaire et secondaire.

Mots-clé: Sistema Nacional de Avaliação do Ensino Básico - Saeb; résultats scolaires; effet de la famille; effet de l'école 